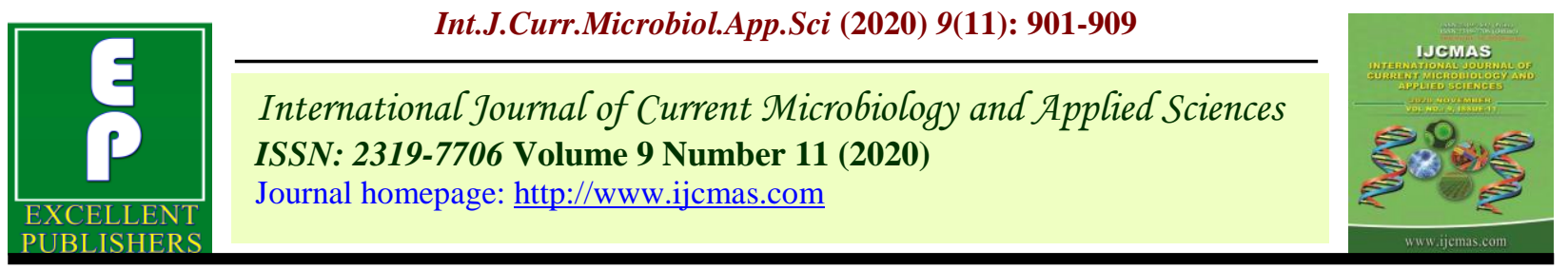

Original Research Article

https://doi.org/10.20546/ijcmas.2020.911.108

\title{
Antifungal Activity of Copper Oxide Nanoparticles against the Fungal Pathogens Isolated from Arid Environment of Jodhpur
}

\author{
Ramesh Chand Kasana*, Sunil Kumar Singh and Praveen Kumar \\ ICAR-Central Arid Zone Research Institute, Jodhpur-342003, India \\ ${ }^{\#}$ Present address: ICAR-Central Institute of Post-Harvest Engineering and Technology, \\ Ludhiana 141004, India \\ *Corresponding author
}

\section{A B S T R A C T}

Ke y w o r d s
Pathogenic fungi,
Inhibition,
Alternaria and
Fusarium

Five plant pathogenic fungi were isolated from infected plants of groundnut, castor and cumin growing under arid environment. The isolates belonged to two fungal genera and were identified as Alternaria tenuissima (CZC-2), Alternaria alternata (CZCU-1), Fusarium equiseti (CZCU-2), Fusarium oxysporum (CZCU-4) and Fusarium solani (CZGN-9) based on ribosomal DNA sequencing. The effect of copper oxide nanoparticles on growth inhibition of these fungal pathogens was carried out in solid and liquid media. In the plate method A. tenuissima (CZC-2) showed the maximum diameter of colony growth in control plates in both the media, whereas the minimum diameter of colony growth was shown by Alternaria tenuissima CZC-2 and Fusarium solani CZGN-9 in the potato dextrose agar (PDA) and rose bengal agar (RBA) supplemented with 500 ppm of copper oxide nanoparticles (CNP), respectively. In the plate method the maximum inhibition of $68.8 \%$ was reported against A. tenuissima CZC-2 in plates supplemented with $500 \mathrm{ppm}$ of copper nanoparticles. Whereas in liquid medium there was complete growth inhibition of $A$. tenuissima $\mathrm{CZC}-2$ and $F$. oxysporum $\mathrm{CZCU}-4$ at $250 \mathrm{ppm}$ concentration of copper oxide nanoparticles.

\section{Introduction}

To feed the increasing world population by improving the agricultural production in sustainable manner is a great challenge being faced agri-researchers. Despite of great strides in agriculture in the last few decades many developing countries are still vulnerable in achieving the food security (Husen and Siddiqi, 2014; Kasana et al., 2017). Agricultural crops face various abiotic and biotic stresses adversely affecting the crop yields which are more severe in arid environments resulting in overall reduction in crop yield. Along with others factors growth of fungal pathogens in plants is one of the main causes for considerable economic loss during the production and postharvest handling of food grains. Prevalence of many plant pathogenic diseases and insect injuries results in the loss of about one-third of plant harvest worldwide (Bramhanwade et al., 2016). India contributes more than $90 \%$ of cumin (Cuminum cyminum L.), $65 \%$ of Castor (Ricinus communis L.) and is the major producer of peanut (Arachis hypogaea L.) at global level (FAOSTAT 2016). The castor oil is commercially valued for 
ricinoleic acid and non-edible oil (Ladda and Kamthane 2014; Jeong and Park 2009), Cumin for cuisines having therapeutic significance (Bettaieb et al., 2011) and as an antioxidant (Nadeem and Riaz, 2012). Peanut is a known major source of edible oil. Nevertheless, incessant attack by various pathogenic fungi causing wilt, root rot and blight diseases is major limiting factors in production of these crops (Chattopadhyay et al., 2016; Sharma and Rana, 2017; Lodha and Mawar, 2007; Singh et al., 2020a, 2020b). The correct molecular identification is a prerequisite for the management of the target pathogens. Nucleotide variations in ITS regions encompassing ITS-1, 5.8S rRNA gene and ITS-2 have been used extensively for molecular diagnostics of pathogens (Jain et al., 2013; Singh et al., 2013; Gautam et al., 2016). Various agrochemical and fungicides are used to control the plant pathogenic fungi resulting in decrease in outbreak of fungal diseases. At the same time continuous application of conventional fungicides has resulted in development of resistance to many fungicides making it difficult to control the plant pathogens. With the advent of biotechnology various metal nanoparticles has been used as antibacterial and antifungal agents for inhibiting the growth of plant pathogens. The scope of copper oxide nanoparticles has been a keen area of interest for the researchers due to their distinguished antibacterial and antifungal activity which has opened new frontiers to biological sciences (Kasana et al., 2017). Inhibition efficiency of copper nanoparticles against fungi is significant than other metal nanoparticles (Servin et al., 2015, Viet et al., 2016). Various pathogenic bacteria belonging to Bacillus subtilis, Enterococcus faecalis, Escherichia coli, Klebsiella pneumonia, Legionella pneumophila, Pseudomonas aeruginosa, Pseudomonas fluorescens, Shigella sonnei, Staphylococcus aureus, Staphylococcus epidermidis and
Xanthomonas campestris has been found to be inhibited by copper nanoparticles (Mahmoodi et al., 2018). Previous research on antifungal effects of copper nanoparticles against plant pathogenic fungi has mostly been carried out without stating the concentrations used (Kanhed et al., 2014, Shende et al., 2015, Bramhanwade et al., 2016). However, there is one report where copper nanoparticles at $450 \mathrm{ppm}$ showed the maximum inhibition of Fusarium sp. growth in the solid medium after 9 days of incubation (Viet et al., 2016). The present study was conducted to observe the effect of copper oxide nanoparticles in both solid and broth culture media against five fungal pathogens isolated from three crops growing in arid environments of Jodhpur.

\section{Materials and Methods}

\section{Isolation of pathogens}

The fungal pathogens were isolated from infected plants of groundnut, castor and cumin. Diseased plant samples were brought to the laboratory and washed thoroughly with distilled water to remove the surface contaminants. The infected plant parts were cut into about 1 inch pieces and surface sterilized using $2 \%$ sodium hypochlorite for 2 minutes and washed three times in sterilized distilled water and aseptically transferred on to petri plates containing PDA medium. The inoculated Petri plates were incubated at $28 \pm$ $2^{\circ} \mathrm{C}$ in a BOD incubator for five days. Pure cultures were raised from peripheral mycelium with a piece of culture media from petri plates into test tubes and again incubated at $28 \pm 2^{\circ} \mathrm{C}$ for 10 days. Pure cultures were then stored at in a refrigerator until used.

\section{DNA isolation}

Fungal mycelium from each pure culture was aseptically transferred to the broth culture 
medium and incubated in a BOD incubator at $28 \pm 2{ }^{\circ} \mathrm{C}$ for one week. The genomic DNA was extracted from approximately $100 \mathrm{mg}$ of fresh mycelium by crushing it in micro centrifuge tubes using micro-pestles in liquid nitrogen. The HiPura kit of HiMedia Company and protocols suggested by Birren \& Lai 1993; Sambrook et al., 1989 were followed for genomic DNA isolation. The DNA was eluted in $200 \mu \mathrm{l}$ of Tris EDTA buffer (TE buffer). The yield and purity of extracted DNA was determined electrophoretically on $0.8 \%$ agarose gel and spectrophotometrically at 260 and $280 \mathrm{~nm}$ wavelength using BioPhotometer (D30, Eppendorf Germany)

\section{Identification of pathogens}

Molecular identification of the fungal strains was done by amplifying the internal transcribed spacer (ITS) region of ribosomal DNA, which encompasses the 5.8S gene from genomic DNA in a thermocycler using ITS-1 (5' TCC GTA GGT GAA CCT GCG G 3') and ITS-4 (5, TCC TCC GCT TAT TGA TAT GC 3') universal primers from each fungal pathogen. Each PCR reaction of $50 \mu \mathrm{l}$ contained: 1x PCR buffer (Sigma Aldrich), $2.5 \mathrm{mM} \mathrm{MgCl}_{2}, 150 \mathrm{mM}$ dNTP mix (Thermo Scientific), 100 pmol of each ITS-1 and ITS-4 primers, 1U Taq DNA polymerase (Sigma Aldrich) and $50 \mathrm{ng}$ genomic DNA. The PCR was initiated by incubating the reaction mixture at $94^{\circ} \mathrm{C}$ for $3 \mathrm{~min}$, followed by 36 cycles of $1 \mathrm{~min}$ at $94{ }^{\circ} \mathrm{C}$, annealing at $55{ }^{\circ} \mathrm{C}$ for $1 \mathrm{~min}$ and extension at $1 \mathrm{~min}$ at $72{ }^{\circ} \mathrm{C}$ and finally extension for $10 \mathrm{~min}$ at $72{ }^{\circ} \mathrm{C}$. The PCR products were separated on $1.6 \%$ agarose gel prepared in $1 \times$ TAE buffer in an electrophoresis run for $100 \mathrm{~min}$ at $60 \mathrm{~V}$. The agarose gel was pre-stained with $12 \mu \mathrm{l}$ of ethidium bromide and photographs captured under UV light using gel documentation system.
The ITS amplified region of each PCR product was sequenced by Sanger di-deoxy sequencing technology employing ABI prism DNA sequencer using universal primers. The BLASTN http://www.ncbi.nlm.nih.gov/BLAST/; National Center for Biotechnology Information, Bethesda, MD) was used for homology searches with the standard program default for identification of fungi.

\section{Phylogenetic analysis}

For phylogenetic analysis the ITS1-5.8SITS2 gene sequences of the species of genus Fusarium and Alternaria were downloaded from NCBI data bases. Multiple sequence alignments of the sequence was performed using CLUSTAL W (Thompson et al., 1994). The evolutionary history was inferred using the Neighbor-Joining method (Saitou and Nei 1987). The evolutionary distances were computed using the Maximum Composite Likelihood method (Tamura et al., 2004). Mucor irregularis was used as out group. All ambiguous positions were removed for each sequence pair and evolutionary analyses were conducted in MEGA X (Kumar et al., 2018).

\section{Antifungal activity}

Copper oxide nanoparticles with $<50 \mathrm{~nm}$ particle size (Sigma Aldrich) were used for antifungal activity. Growth of fungi and antifungal activity/inhibition assays were performed in different media; solid media and liquid medium.

\section{In solid media}

To study the antifungal activity of copper oxide nanoparticles in solid media the growth of five pathogenic fungi in following media was checked and compared i) PDA ii) PDA having 250 ppm CNP iii) PDA having 500 ppm CNP iv) rose bengal agar (RBA) v) RBA 
having 250 ppm CNP vi) RBA having 500 ppm CNP. Solidified plates of media described above prepared and with then with the help of cork borer fungal discs of $7 \mathrm{~mm}$ diameter were transfer on to these plates. Plates incubated at $28 \pm 2{ }^{\circ} \mathrm{C}$ and the diameter of the fungal colonies was determined after the incubation periods of 9 days. The inhibition efficiency of fungal plant pathogens was calculated by using formula as suggested by Vincent (1947).

$$
\mathbf{I}=\frac{\mathrm{C}-\mathrm{T}}{\mathrm{C}} \times 100
$$

Where, $\mathrm{I}$ is inhibition percentage; $\mathrm{C}$ is growth of fungal plant pathogens in control plates (cm), and $\mathrm{T}$ is growth of fungal pathogens in CNP supplemented plates $(\mathrm{cm})$.

\section{In liquid medium}

To study the effect of nanoparticles on growth of fungi in the liquid media the different pathogenic fungi were grown i) potato dextrose broth medium (PDB), ii) PDB with 250 ppm CNP iii) PDB with 500 ppm CNP.

Different fungal cultures were inoculated into $100 \mathrm{ml}$ of the above medium and incubated at $28 \pm 2{ }^{\circ} \mathrm{C}$. The flasks were observed for growth up to 7 days of incubation then the fungal samples were filtered through filter paper. Then the paper with fungal filtrate was observed to determine the fungal biomass.

\section{Results and Discussion}

\section{Isolation and identification}

Five pathogenic fungal isolates designated as CZC-2 from castor, CZCU-1, CZCU-2 and CZCU-4 from cumin and CZGN-9 from groundnut were selected for the studies. After preliminary microscopic observations the identification of fungal pathogens; was conducted based on the sequencing ITS15.8S-ITS2 region. The different fungal isolates CZC-2, CZCU-1, CZCU-2, CZCU-4 and CZGN-9 showed a homology of 100, 100, 99.81, 99.81 and $100 \%$ with Alternaria tenuissima strain SF8, Alternaria alternata strain 032, Fusarium equiseti strain CBS 259.54, Fusarium oxysporum strain IHB F 2916 and Fusarium solani strain CBS 127306 respectively with published species in the literature (Zhao et al., 2018, Oliveira et al., 2018, Vu et al., 2019). Based on their homology the isolates were identified as Alternaria tenuissima CZC-2, Alternaria alternata $\mathrm{CZCU}-1$, Fusarium equiseti CZCU2, Fusarium oxysporum CZCU-4 and Fusarium solani CZGN-9. Fungal pathogens belonging to various species of genus Alternaria and Fusarium have been isolated from castor, cumin and groundnut, and identified by morphological and molecular methods (Zaman and Ahmed, 2012; Ozer and Bayraktar, 2015; Sharma and Rana, 2017). Sequences of all the fungi were submitted to NCBI with accession numbers MF166760, MF166764, MF166765, MF166767 and MF166779 respectively. Ssequences of the isolates were then aligned and compared with previously published sequences of the species from genus Fusarium and Alternaria and a neighbor-joining phylogenetic trees was constructed using MEGA X (Kumar et al., 2018). In phylogenetic analysis the three species of Fusarium formed three different clusters while the two species of Alternaria were grouped in a single cluster (Fig. 1).

\section{Antifungal properties of copper nanoparticles against various pathogens}

The effect of copper oxide nanoparticles of $>$ $50 \mathrm{~nm}$ size on development of five pathogens belonging to two genera and five species was observed by determining the diameter of the fungal colonies on two fungal culture media. The growth of each pathogenic fungi was observed both in control medium and treatment medium supplemented with copper oxide nanoparticles. 
Fig.1 Phylogenetic tree based on ITS1-5.8S-ITS2 region sequences, drawn using the neighbor joining method and showing the relationship between Alternaria tenuissima CZC-2, Alternaria alternata CZCU-1, Fusarium equiseti CZCU-2 Fusarium oxysporum CZCU-4 and Fusarium solani CZGN-9 and species from genus Alternaria and Fusarium. The sequences were downloaded from NCBI database. Mucor irregularis was used to root the tree. Bar, 0.05 substitutions per site. Evolutionary analyses were conducted in MEGA X

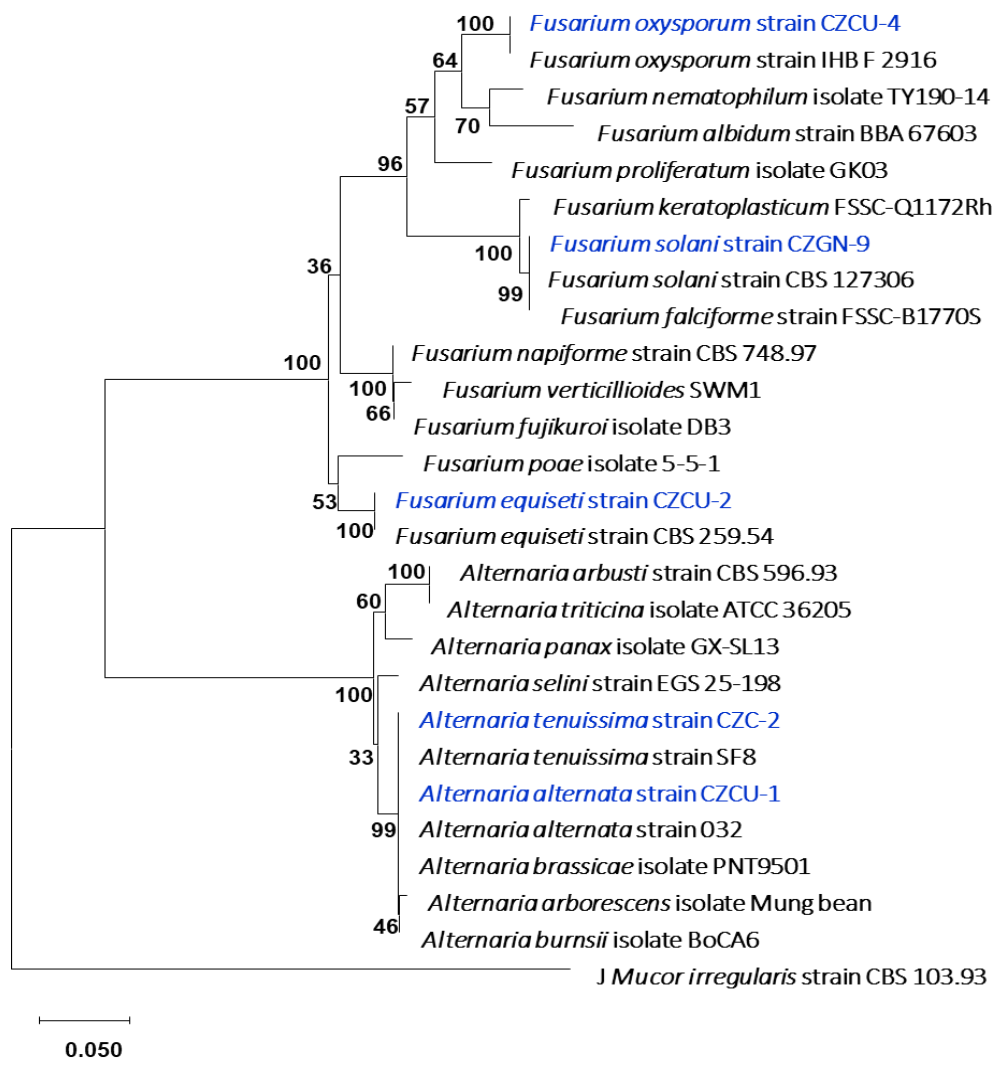

Fig.2 The diameter of colonies of various fungi in the control (PDA) and treatment (PDA+500 ppm of CNP) after 9 days of incubation

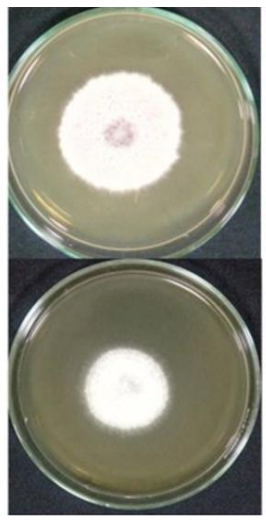

Fusarium solani CZGN-9

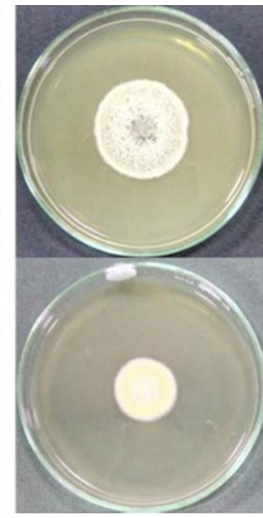

Alternaria alternata CZCU-1

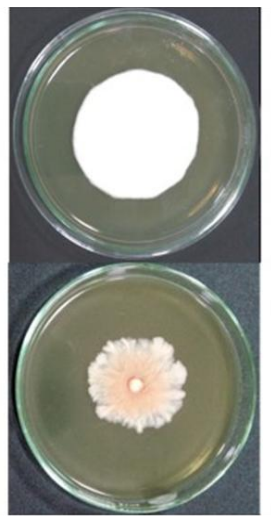

Fusarium equiseti CZCU-2

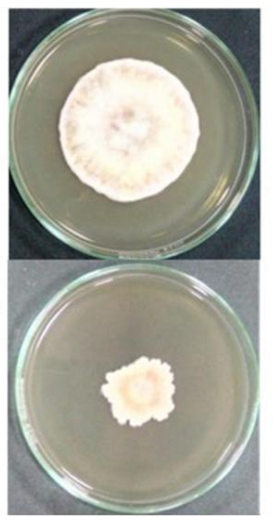

Fusarium oxysporum CZCU-4

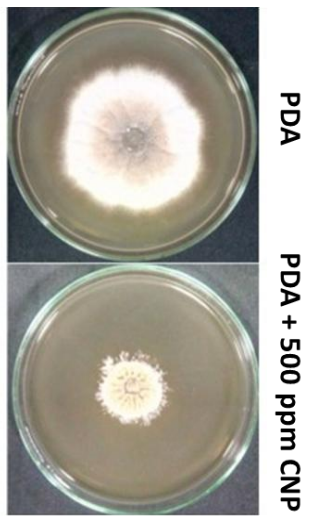

Alternaria tenuissima CZC-2 
Fig.3 Colony diameter of various pathogenic fungi in potato dextrose agar (control and treatment plates) after incubation for 9 days

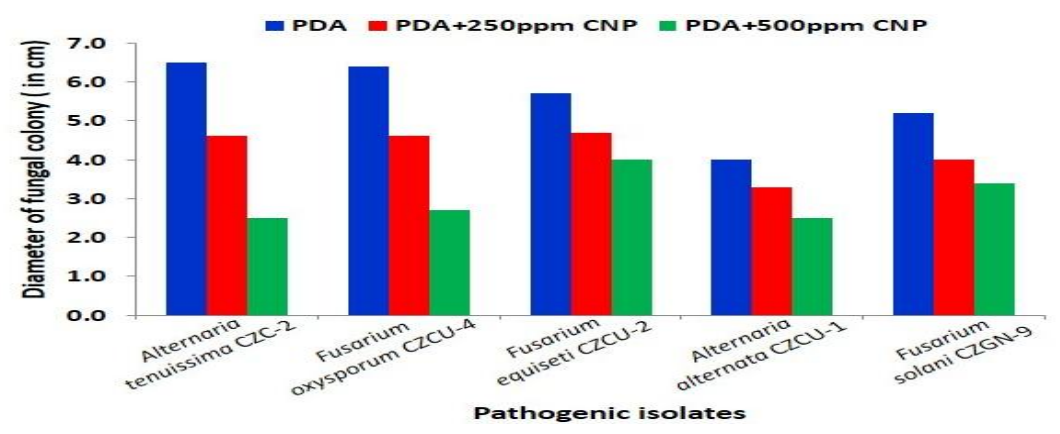

Fig.4 Colony diameter of various pathogenic fungi in rose bengal agar (control and treatment plates) after incubation for 9 days

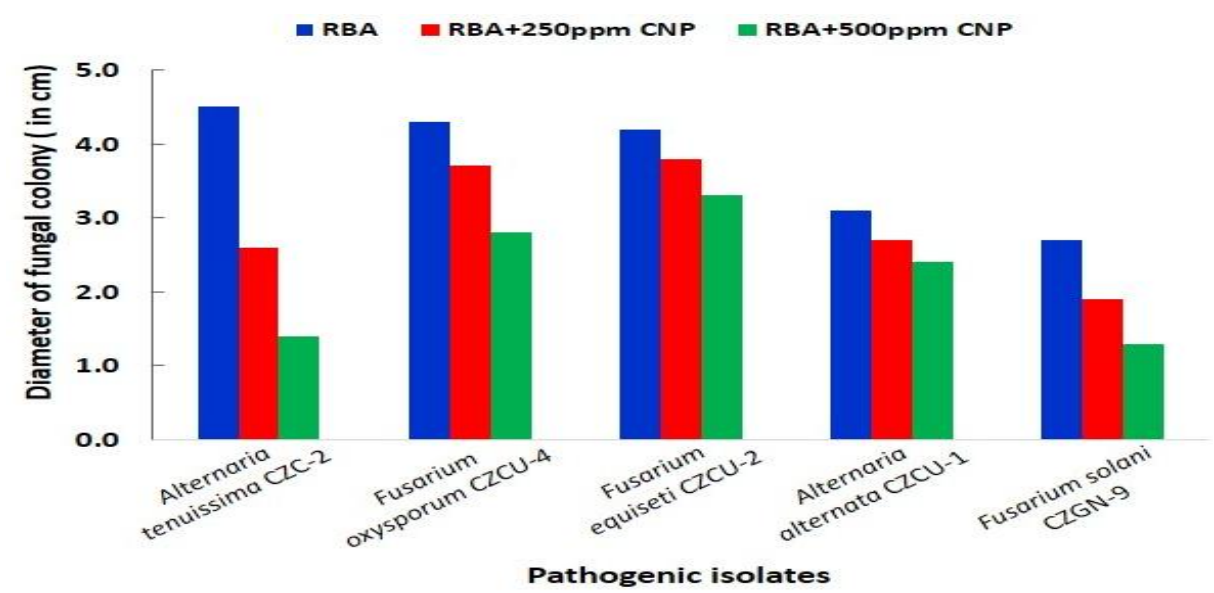

Fig.5 The inhibition efficiency of copper oxide nanoparticles at $250 \mathrm{ppm}$ and $500 \mathrm{ppm}$ against various pathogenic fungi

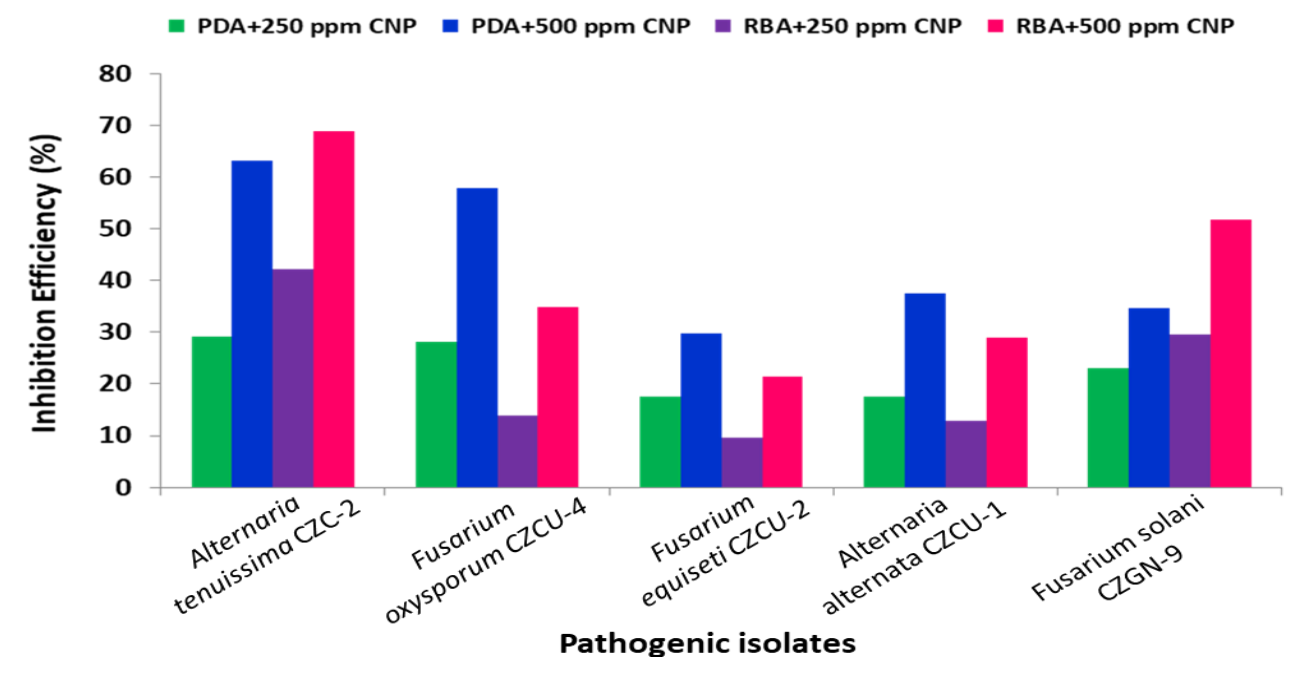


Fig.6 The fungal biomass of pathogenic fungi in potato dextrose broth and potato dextrose broth +250 ppm of CNP
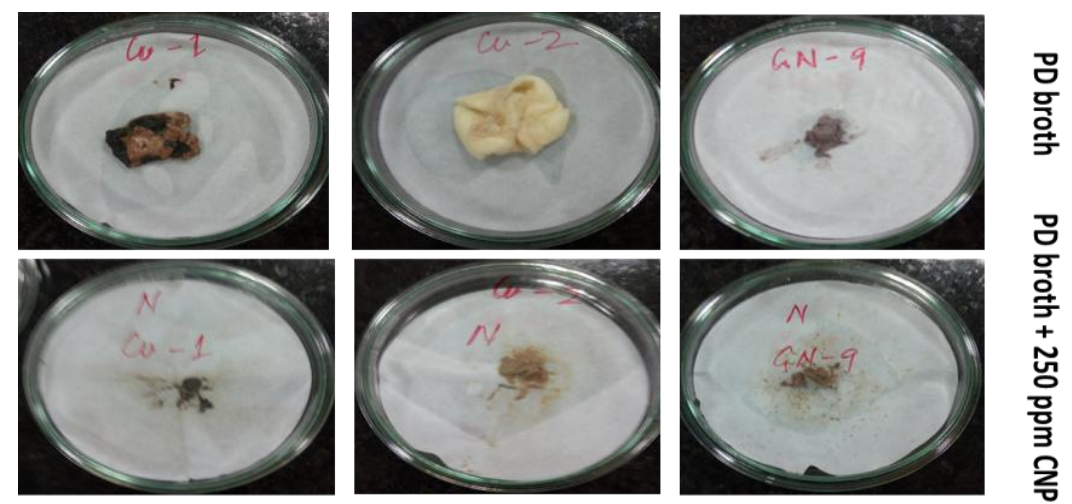

The representative images of growth of colonies of various test pathogenic fungi in PDA medium (control) and medium supplemented with $500 \mathrm{ppm}$ of copper oxide nanoparticles are shown (Fig. 2). Similar pattern was observed in case of rose bengal agar culture medium supplemented with copper oxide nanoparticles. From the results it is evident that addition of copper oxide nanoparticles inhibited the growth of all the five pathogens tested; A. tenuissima, $A$. alternata, $F$. equiseti, $F$. oxysporum and $F$. solani. The diameter of fungal colonies of various test pathogens on PDA and PDA supplemented with $250 \mathrm{ppm}$ and $500 \mathrm{ppm}$ CNP and RBA and RBA supplemented with $250 \mathrm{ppm}$ and $500 \mathrm{ppm}$ CPM is shown in figures (Fig. 3 and Fig. 4). The maximum diameter of colony growth was observed in case of A. tenuissima CZC-2 in control plates in both the media. The minimum diameter of colony growth was shown by A. tenuissima CZC-2 and $F$. solani CZGN-9 in the PDA and RBA supplemented with 500 ppm of CNP respectively. It was also observed that the fungal mat was thin in case of medium mixed with copper oxide nanoparticles as compared to the control.

From the data on growth the inhibition efficiency of copper oxide nanoparticles calculated at two different concentrations in two different media against five pathogenic fungi is shown in figure (Fig. 5). Results showed good inhibition efficiency of copper nanoparticles against all the pathogens in Petri plate method. The inhibition efficiency of copper oxide nanoparticles was concentration dependent and found to increase with increase in the concentration used. The maximum inhibition of $68.8 \%$ and $63.3 \%$ respectively were reported against Alternaria tenuissima CZC-2 in rose bengal agar and potato dextrose agar supplemented with $500 \mathrm{ppm}$ of copper oxide nanoparticles. Further the growth of different pathogenic fungi was observed in potato dextrose broth supplemented with copper oxide nanoparticles. It was interesting to report that in none of the fungi was able to grow in the broth medium supplemented with $500 \mathrm{ppm}$ of copper oxide nanoparticles. Even at $250 \mathrm{ppm}$ there was no growth of two fungal isolates ( $A$. tenuissima and $F$. oxysporum) while other three isolates also showed very less growth at this concentration (Fig. 6). Antifungal activity of copper oxide nanoparticles against many pathogenic fungi belong to various genera Phoma, Curvularia, Alternaria, and Fusarium using the inhibition zone method have been carried without providing the concentrations of copper nanoparticles (Kanhed et al., 2014, Shende et al., 2015, Bramhanwade et al., 2016). In another study on effect of copper 
oxide nanoparticles against a single isolate of Fusarium sp. showed maximum inhibition of growth at $450 \mathrm{ppm}$ in the solid medium after 9 days of incubation (Viet et al., 2016).

In conclusion the five pathogenic fungi belonging to two genera and five species were isolated from infected plants of groundnut, castor and cumin growing under arid environment and molecularly identified. In the plate assay inhibition of $68.8 \%$ and 63.3 $\%$, respectively was observed against Alternaria tenuissima in rose bengal agar and potato dextrose agar supplemented with 500 ppm of copper oxide nanoparticles. While in case of liquid medium at $250 \mathrm{ppm}$ concentration there was complete inhibition of Alternaria tenuissima and Fusarium oxysporum and other three isolates also showed very less growth.

\section{Acknowledgements}

Authors are thankful to the Director, ICARCentral Arid Zone Research Institute, Jodhpur for providing necessary facilities and support. The financial assistance received under the project CRP on nanotechnology is duly acknowledged.

\section{References}

Bettaieb I, Bourgou S, Sriti J, Msaada K, Limam F and Marzouk B (2011). Essential oils and fatty acids composition of Tunisian and Indian cumin (Cuminum cyminum L.) seeds: a comparative study. $J$ Sci Food Agri., 91: 2100-2107.

Birren B and Lai E (1993). Pulsed field gel electrophoresis: a practical guide. Academic Press, San Diego, p. 253.

Bramhanwade K, Shende S, Bonde S, Gade A, Rai M (2016). Fungicidal activity of $\mathrm{Cu}$ nanoparticles against Fusarium causing crop diseases. Environ Chem Lett., 14(2):229-235. doi:10.1007/ s10311-0150543-1
Chattopadhyay C, Kolte SJ and Waliya F (2016). Section II. Peanut, in: Diseases of edible oilseed crops. Pages 13-145. CRC Press Taylor \& Francis Group, 6000 Broken Sound Parkway NW, Suite 300, Boca Raton, FL 33487-2742.

FAOSTAT (2016) www.fao.org/faostat/en/ \#data/QC/. Accessed 6 December, 2018

Gautam R, Singh SK and Sharma V (2016). Molecular diagnosis and intraspecific genetic variability of root pathogens of arid legumes in Western Rajasthan, India. Revista de Biologia. Tropical. Vol. 64 (4): 1505-1518

Husen A and Siddiqi KS (2014). Phytosynthesis of nanoparticles: concept, controversy and application. Nanoscale Res Lett., 9:229. doi:10.1186/1556-276X-9-229

Jain N, Bhargava A, Tarafdar JC, Singh SK and Panwar J (2013). A biomimetic approach towards synthesis of $\mathrm{ZnO}$ nanoparticles. Appl Microbiol Biotechnol., 97: 859-869.

Jeong GT and Park DH (2009). Optimization of biodiesel production from castor oil using response surface methodology. Appl Biochem Biotechnol 156: 431-441

Kanhed P, Birla S, Gaikwad S, Gade A, Seabra AB, Rubilar O, Duran N, Rai M (2014). In vitro antifungal efficacy of copper nanoparticles against selected crop pathogenic fungi. Mater Lett., 115:13-17. doi:10.1016/j.matlet.2013.10.011

Kasana RC, Panwar NR, Kaul RK, Kumar P (2017). Biosynthesis and effects of copper nanoparticles on plants. Environ. Chem. Lett., 15, 233-240. doi:10.1007/s10311017-0615-5

Kumar S., Stecher G., Li M., Knyaz C., and Tamura K. (2018). MEGA X: Molecular Evolutionary Genetics Analysis across computing platforms. Molecular Biol Evol., 35:1547-1549.

Ladda PL, Kamthane RB (2014). Ricinus communis (castor): an overview. Int J Res Pharmacol Pharmacotherapeutics 3(2): 136-144

Lodha SK, Mawar R (2007). Integrated disease management in seed spices. In: Mahotra SK, Vashistha BB (eds.). Production, 
Development, Quality and Export of Seed Spices. Ajmer National Research Centre on Seed Spices, 119-138.

Mahmoodi S, Elmi A, Nezhadi H (2018) Copper nanoparticles as antibacterial agents. J Mol Pharm Org Process Res., 6: 140.

Nadeem M, Riaz A, 2012. Cumin (Cuminum cyminum) as a potential source of antioxidants Pakistan J Food Sci., 22: 101-107.

Saitou N. and Nei M. (1987). The neighborjoining method: A new method for reconstructing phylogenetic trees. Molecular Biol Evol., 4: 406-425.

Sambrook J, Fritsch EF \& Maniatis T (1989). Molecular cloning: a laboratory manual, 2nd edn. Cold Spring Harbor Laboratory Press, Plainview

Servin A, Elmer W, Mukherjee A, De la Torre-Roche R, Hamdi H, White JC, Bindraban P and Dimkpa C (2015) A review of the use of engineered nanomaterials to suppress plant disease and enhance crop yield. J Nanoparticle Res., 17(2): 1-21.

Sharma DK, Rana S (2017) Seed-borne and post-harvest diseases of castor bean (Ricinus communis linn.) and their management: a review. J Phytol Res., 30(1): 31-45

Shende S, Ingle AP, Gade A, Rai M (2015) Green synthesis of copper nanoparticles by Citrus medica Linn. (Idilimbu) juice and its antimicrobial activity. World $J$ Microbiol Biotechnol., 31(6):865-873. doi:10.1007/s11274-015-1840-3

Singh SK, Doshi A, Pancholy A and Pathak R
(2013) Biodiversity in wood-decay macrofungi associated with declining arid zone trees of India as revealed by nuclear rDNA analysis. Europ J Plant Pathol., 136: 373-382

Singh SK, Jadon KS, Patel N. and Sharma AK (2020a). Development of a prophylactic integrated pest management module for groundnut (Arachis hypogaea L.), Int $J$ Pest Manag, DOI: 0.1080/ 09670874.2020.1791371

Singh SK, Patel N, Jadon KS and Sharma AK (2020b). Bio-intensive Prophylactic Integrated Pest Management in Castor for Arid Environment. Proc. Natl. Acad. Sci., India, Sect. B Biol. Sci. https://doi.org/10.1007/s40011-02001174-2

Tamura K, Nei M and Kumar S (2004). Prospects for inferring very large phylogenies by using the neighbor-joining method. Proceedings of the National Academy of Sciences (USA) 101:1103011035.

Thompson JD, Higgins DG, Gibson DJ (1994) CLUSTAL W: improving the sensitivity of progressive multiple sequence weighing, position specific gap penalties and weight matrix choice. Nucleic Acid Res., 22:4673-4680

Viet PV, Nguyen HT, Cao TM, Hieu LV (2016) Fusarium antifungal activities of copper nanoparticles synthesized by a chemical reduction method. J Nanomater., doi:10.1155/2016/1957612.

Vincent JM (1947) Distortion of fungal hyphæ in the presence of certain inhibitors, Nature, 159 (4051): 850.

\section{How to cite this article:}

Ramesh Chand Kasana, Sunil Kumar Singh and Praveen Kumar. 2020. Antifungal Activity of Copper Oxide Nanoparticles against the Fungal Pathogens Isolated from Arid Environment of Jodhpur. Int.J.Curr.Microbiol.App.Sci. 9(11): 901-909.

doi: https://doi.org/10.20546/ijcmas.2020.911.108 